\title{
PRICING THE PRICELESS: COST-BENEFIT ANALYSIS OF ENVIRONMENTAL PROTECTION
}

\author{
FRANK ACKERMAN $^{\dagger}$ \& LISA HEINZERLING ${ }^{\dagger \dagger}$
}

\section{INTRODUCTION}

Many analytical approaches to setting environmental standards require some consideration of costs and benefits. Even technologybased regulation, maligned by cost-benefit enthusiasts as the worst form of regulatory excess, typically entails consideration of economic costs. Cost-benefit analysis differs, however, from other analytical approaches in the following respect: it demands that the advantages and disadvantages of a regulatory policy be reduced, as far as possible, to numbers, and then further reduced to dollars and cents. In this feature of cost-benefit analysis lies its doom. Indeed, looking closely at the products of this pricing scheme makes it seem not only a little cold, but a little crazy as well.

Consider the following examples, which we are not making up. They are not the work of a lunatic fringe, but, on the contrary, they reflect the work products of some of the most influential and reputable of today's cost-benefit practitioners. We are not sure whether to laugh or cry; we find it impossible to treat these studies as serious contributions to a rational discussion.

Several years ago, states were in the middle of their litigation against tobacco companies, seeking to recoup the medical expenditures they had incurred as a result of smoking. At that time, W. Kip Viscusi-a professor of law and economics at Harvard and the primary source of the current $\$ 6.3$ million estimate for the value of a statistical life'-undertook research concluding that states, in fact, saved money

\footnotetext{
${ }^{\dagger}$ Research Director, Global Development and Environment Institute, Tufts University.

${ }^{\text {"P }}$ Professor of Law, Georgetown University Law Center.

This Article explores ideas more fully presented in our forthcoming book, Priceless: Human Health, THE ENVIRONMENT, and the Limits of the Market (forthcoming 2002). This Article also draws upon a monograph of the same title published by the Georgetown Environmental Law and Policy Institute in 2002.

' W. KIP VisCUSI, RATIONAL RISK POLICY 46 (1998).
} 
as the result of smoking by their citizens. ${ }^{2}$ Why? Because they died early! $^{3}$ They thus saved their states the trouble and expense of providing nursing home care and other services associated with an aging population. ${ }^{4}$

Viscusi didn't stop there. So great, under Viscusi's assumptions, were the financial benefits to the states of their citizens' premature deaths that, he suggested, "cigarette smoking should be subsidized rather than taxed."

Amazingly, this cynical conclusion has not been swept into the dustbin where it belongs, but instead recently has been revived: the tobacco company Philip Morris commissioned the well-known consulting group Arthur D. Little to examine the financial benefits to the Czech Republic of smoking among Czech citizens. Arthur D. Little International, Inc., found that smoking was a financial boon for the government-partly because, again, it caused citizens to die earlier and thus reduced government expenditure on pensions, housing, and health care. ${ }^{6}$ This conclusion relies, so far as we can determine, on perfectly conventional cost-benefit analysis.

There is more. In recent years, much has been learned about the special risks children face due to pesticides in their food, contaminants in their drinking water, ozone in the air, and so on. Because cost-benefit analysis has become much more prominent at the same time, there is now a budding industry in valuing children's health. Its products are often bizarre.

Take the problem of lead poisoning in children. One of the most serious and disturbing effects of lead contamination is the neurological damage it can cause in young children, including permanently diminished mental ability. Putting a dollar value on the (avoidable, environmentally caused) retardation of children is a daunting task, but economic analysts have not been deterred.

Randall Lutter, a frequent regulatory critic and a scholar at the AEI-Brookings Joint Center for Regulatory Studies, argues that the

\footnotetext{
${ }^{2}$ W. Kip Viscusi, Cigarette Taxation and THE Social Consequences of SMOKING 47 (Nat'l Bureau of Econ. Research, Working Paper No. 4891, 1994), available at http://papers.nber.org/papers/w4891.pdf.

${ }^{3}$ Id.

${ }^{4} I d$.

${ }^{5}$ Id. at 33 (emphasis added).

${ }^{6}$ ARThur D. LitTle INT'L, Inc., Public Finance Balance of SMOKIng IN THE CZECH REPUBLIC 2 (2000), available at http://europe.cnn.com/2001/BUSINESS/07/ 16/czech.morris/study.doc.
} 
way to value the damage lead causes in children is to look at the amount parents of affected children spend on chelation therapy, a chemical treatment that is supposed to cause excretion of lead from the body. ${ }^{7}$ Parental spending on chelation supports an estimated valuation of as low as $\$ 1100$ per IQ point lost due to lead poisoning. ${ }^{8}$ Previous economic analyses by the EPA, based on the children's loss of expected future earnings, have estimated the value to be much higher-up to $\$ 9000$ per IQ point. ${ }^{9}$ Based on his lower figure, Lutter claims to have discovered that too much effort is going into controlling lead: "Hazard standards that protect children far more than their parents think is appropriate may make little sense"; thus, "[t]he agencies should consider relaxing their lead standards."

In fact, Lutter presents no evidence about what parents think, only about what they spend on one rare variety of private medical treatment (which, as it turns out, has not been proven medically effective for chronic, low-level lead poisoning)." mental standards be based on what individuals are now spending on desperate personal efforts to overcome social problems?

For sheer analytical audacity, Lutter's study faces some stiff competition from another study concerning kids-this one concerning the value, not of children's health, but of their lives. In this second study, researchers examined mothers' car-seat fastening practices. ${ }^{12}$ They calculated the difference between the time required to fasten the seats correctly and the time mothers actually spent fastening their children into their seats. ${ }^{13}$ Then they assigned a monetary value to this difference of time based on the mothers' hourly wage rate (or, in the case of nonworking moms, based on a guess at the wages they might have earned). ${ }^{14}$ When mothers saved time-and, by hypothesis, money-by fastening their children's car seats incorrectly, they were,

${ }^{7}$ Randall LutTer, Valuing Children's Health: A REassessment of THE BENEFITS OF LOWER LEAD LEVELS 3 (AEI-Brookings Joint Ctr. for Regulatory Studies, Working Paper No. 00-02, 2000), available at http://www.aei.brookings.org/ publications/working/working_00_02.pdf.

${ }^{8} I d$. at 5.

${ }^{9}$ EPA, Economic ANAlysis of Toxic SubStances Control ACt Section 403: HAZARD STANDARDS, at ch. 5 (1998).

${ }^{10}$ LUTTER, supra note 7 , at 3 .

"Id.

12 Paul S. Carlin \& Robert Sandy, Estimating the Implicit Value of a Young Child's Life, 58 S. ECON. J. 186 (1991).

${ }_{14}^{13}$ Id. at $192-96$.

${ }^{14} I d$. 
according to the researchers, implicitly placing a finite monetary value on the life-threatening risks to their children posed by car accidents. ${ }^{15}$

Building on this calculation, the researchers were able to answer the vexing question of how much a statistical child's life is worth to its mother. (As the mother of a statistical child, she is naturally adept at complex calculations comparing the value of saving a few seconds versus the slightly increased risk to her child!) The answer parallels Lutter's finding that we are valuing our children too highly: in car-seatland, a child's life is worth only about $\$ 500,000$. $^{16}$

In this Article, we try to show that the absurdity of these particular analyses, though striking, is not unique to them. Indeed, we will argue, cost-benefit analysis is so inherently flawed that if one scratches the apparently benign surface of any of its products, one finds the same kind of absurdity. But before launching into this critique, it will be useful first to establish exactly what cost-benefit analysis is, and why one might think it is a good idea.

\section{DOLlaRS AND DiscountiNG}

Cost-benefit analysis tries to mimic a basic function of markets by setting an economic standard for measuring the success of the government's projects and programs. That is, cost-benefit analysis seeks to perform, for public policy, a calculation that happens routinely in the private sector. In evaluating a proposed new initiative, how do we know if it is worth doing? The answer is much simpler in business than in government.

Private businesses, striving to make money, only produce things that they believe someone is willing to pay for. That is, firms only produce things for which the benefits to consumers, measured by consumers' willingness to pay for them, are expected to be greater than the costs of production. It is technologically possible to produce men's business suits in brightly colored polka dots. Nonetheless, successful producers suspect that no one is willing to pay for such products, and usually stick to, at most, minor variations on suits in somber, traditional hues. If some firm did happen to produce a polka-dotted business suit, no one would be forced to buy it; the producer would bear the entire loss resulting from the mistaken decision.

Government, in the view of many critics, is in constant danger of

\footnotetext{
15 Id. at 197.

${ }^{16}$ Id. at 196.
} 
drifting toward producing polka-dot suits-and making people pay for them. Policies, regulations, and public spending do not face the test of the marketplace; there are no consumers who can withhold their dollars from the government until it produces the regulatory equivalent of navy blue and charcoal gray. There is no single quantitative objective for the public sector comparable to profit maximization for businesses. Even with the best of intentions, critics suggest, government programs can easily go astray for lack of an objective standard by which to judge whether or not they are meeting citizens' needs.

Cost-benefit analysis sets out to do for government what the market does for business: add up the benefits of a public policy and compare them to the costs. The two sides of the ledger raise very different issues.

\section{A. Estimating Costs}

The first step in a cost-benefit analysis is to calculate the costs of a public policy. For example, the government may require a certain kind of pollution control equipment, for which businesses must pay. Even if a regulation is less detailed and only sets a ceiling on emissions, it results in costs that can be at least roughly estimated through research into available technologies and business strategies for compliance.

The costs of protecting human health and the environment through the use of pollution control devices and other approaches are, by their very nature, measured in dollars. Thus, at least in theory, the cost side of cost-benefit analysis is relatively straightforward. In practice, as we shall see, it is not quite that simple.

The consideration of the costs of environmental protection is not unique to cost-benefit analysis. Development of environmental regulations has almost always involved consideration of economic costs, with or without formal cost-benefit techniques. What is unique to cost-benefit analysis, and far more problematic, is the other side of the balance, the monetary valuation of the benefits of life, health, and nature itself.

\section{B. Monetizing Benefits}

Since there are no natural prices for a healthy environment, costbenefit analysis requires the creation of artificial ones. This is the hardest part of the process. Economists create artificial prices for health and environmental benefits by studying what people would be 
willing to pay for them. One popular method, called "contingent valuation," is essentially a form of opinion poll. Researchers ask a cross section of the affected population how much they would be willing to pay to preserve or protect something that can't be bought in a store. ${ }^{17}$

Many surveys of this sort have been done, producing prices for things that appear to be priceless. For example, the average American household is supposedly willing to pay $\$ 257$ to prevent the extinction of bald eagles, $\$ 208$ to protect humpback whales, and $\$ 80$ to protect gray wolves. ${ }^{18}$ These numbers are quite large: since there are about 100 million households in the country, ${ }^{19}$ the nation's total willingness to pay for the preservation of bald eagles alone is ostensibly more than $\$ 25$ billion.

An alternative method of attaching prices to unpriced things infers what people are willing to pay from observation of their behavior in other markets. To assign a dollar value to risks to human life, for example, economists usually calculate the extra wage-or "wage premium"-that is paid to workers who accept riskier jobs. Suppose that two jobs are comparable, except that one is more dangerous and better paid. If workers understand the risk and voluntarily accept the more dangerous job, then they are implicitly setting a price on risk by accepting the increased risk of death in exchange for increased wages.

What does this indirect inference about wages say about the value of a life? A common estimate in recent cost-benefit analyses is that avoiding a risk that would lead, on average, to one death is worth roughly $\$ 6.3$ million. ${ }^{20}$ This number, in particular, is of great impor-

${ }^{17}$ For a recent review of the literature on nonmarket valuation (the title of which coincidentally bears a strong resemblance to our own), see V. Kerry Smith, Pricing What Is Priceless: A Status Report on Non-Market Valuation of Environmental Resources, in INTERNATIONAL YEARBOOK OF ENVIRONMENTAL AND RESOURCE ECONOMICS, 1997/1998: A SURVEY OF CURRENT ISSUES 156 (Hank Folmer \& Tim Tietenberg eds., 1997).

${ }^{18}$ John B. Loomis \& Douglas S. White, Economic Benefits of Rare and Endangered Species: Summary and Meta-analysis, 18 ECOLOGICAL ECON. 197, 199 tbl.1 (1996) (figures converted to year 2000 dollars by the authors using the consumer price index).

${ }^{19}$ Population Div., U.S. Census Bureau, Estimates of Housing Units, HOUSEHOLDS, HOUSEHOLDS BY AGE OF HOUSEHOLDER, AND PERSONS PER HOUSEHOLD: JULY 1, 1998 (1998), http://eire.census.gov/popest/archives/household/sthuhh1.txt.

${ }^{20}$ The original calculation, based on research by $W$. Kip Viscusi, can be found in EPA, THE BENEFITS AND COSTS OF THE CLEAN AIR ACT, 1970 TO 1990, at app. I (1997), available at http://www.epa.gov/air/sect812/copy.html. For an example of a subsequent analysis citing the Clean Air Act analysis and adjusting only for inflation, see EPA, ARSENIC IN DRINKING WATER RULE: ECONOMIC ANALYSIS 5-23 (2000) [hereinafter EPA, ARSENIC STUDY], available at http://www.epa.gov/safewater/ars/ 
tance in cost-benefit analyses because avoided deaths are the most thoroughly studied benefits of environmental regulations.

\section{Discounting the Future}

One final step in this quick sketch of cost-benefit analysis requires explanation. Costs and benefits of a policy frequently occur at different times. Often, costs are incurred today, or in the near future, to prevent harm in the more remote future. When the analysis spans a number of years, future costs and benefits are discounted, or treated as equivalent to smaller amounts of money in today's dollars.

Discounting is a procedure developed by economists in order to evaluate investments that produce future income. The case for discounting begins with the observation that $\$ 100$ received today is worth more than $\$ 100$ received next year, even in the absence of inflation. For one thing, you could put your money in the bank today and earn interest by next year. Suppose that your bank account earns $3 \%$ interest per year. In that case, if you received the $\$ 100$ today rather than next year, you would earn $\$ 3$ in interest, giving you a total of $\$ 103$ next year. Likewise, in order to get $\$ 100$ next year you only need to deposit $\$ 97$ today. ${ }^{21}$ So, at a $3 \%$ discount rate, economists would say that $\$ 100$ next year has a present value of $\$ 97$ in today's dollars.

For longer periods of time, the effect is magnified: at a $3 \%$ discount rate, $\$ 100$ twenty years from now has a present value of only $\$ 55$. The larger the discount rate, and/or the longer the time intervals involved, the smaller the present value: at a $5 \%$ discount rate, for example, $\$ 100$ twenty years from now has a present value of only $\$ 38$.

Cost-benefit analysis routinely uses the present value of future benefits; that is, it compares current costs, not to the actual dollar value of future benefits, but to the smaller amount you would have to put into a hypothetical savings account today to obtain those benefits in the future. This application of discounting is essential, and indeed commonplace, for many practical financial decisions. If offered a choice of investment opportunities with payoffs at different times in the future, you can (and should) discount the future payoffs to the present in order to compare them to each other. The important issue for environmental policy, as we shall see, is whether this logic also ap-

econ_analysis.pdf. The arsenic study used $\$ 6.1$ million in 1999 dollars, id., which is equivalent to $\$ 6.3$ million in 2000 dollars.

${ }^{21}$ The examples in the text are rounded off to the nearest dollar. The actual present value, rounded to the nearest cent, would be $\$ 97.09$. 
plies to outcomes far in the future, and to opportunities-like long life and good health-that are not naturally stated in dollar terms.

\section{THE CASE FOR COST-BENEFIT}

Before describing the problems with cost-benefit analysis, it will be useful to set forth the arguments in favor of this type of analysis. Many different arguments for cost-benefit analysis have been offered over the years. Most of the arguments fall into one of two broad categories. First, there are economic assertions that better results can be achieved with cost-benefit analysis. Second, there are legal and political claims that a more objective and open government process can emerge through this kind of analysis.

\section{A. Better Results}

Economics frequently focuses on increasing efficiency-on getting the most desirable results from the least resources. How do we know that greater regulatory efficiency is needed? For many economists, this is an article of faith: greater efficiency is always a top priority, in regulation or elsewhere. Cost-benefit analysis supposedly furthers efficiency by ensuring that regulations are only adopted when benefits exceed costs and by helping direct regulators' attention to those problems for which regulatory intervention will yield the greatest net benefits.

But many advocates also raise a more specific argument, imbued with a greater sense of urgency. The government, it is said, often issues rules that are insanely expensive, out of all proportion to their benefits-a problem that could be solved if proposed regulations were screened through cost-benefit analysis. Thus much of the case for costbenefit analysis depends on the case against current regulation.

Scarcely a congressional hearing on environmental policy occurs in which fantastic estimates of the costs of federal regulations do not figure prominently. Economists routinely cite such estimates as proof of the need for more economic analysis. Browse the websites of any of a variety of think tanks, and you will find numerous references to the extravagant costs of regulation.

The estimates typically bandied about are astonishingly high: according to several widely circulated studies, we often spend hundreds of millions, and sometimes billions, of dollars for every single human 
life, or even year of life, we save through regulation. ${ }^{22}$ One widely cited study claims that the cost of life-saving interventions can reach as high as $\$ 99$ billion for every life-year saved. ${ }^{23}$ Numbers like these have been used to argue that current regulatory costs are not only chaotically variable but also unacceptably high. They even have been relied upon to claim that the existing regulatory system actually kills people by imposing some very costly life-saving requirements while other, less expensive and more effective life-saving possibilities remain untouched. Indeed, one study concluded that we could save as many as sixty thousand more lives every year, with no increase in costs, if we simply spent our money on the least rather than most expensive opportunities for saving lives. ${ }^{24}$ Relying on this research (of which he was a coauthor), John Graham, the current head of the Office of Information and Regulatory Affairs in the Office of Management and Budget, and a prominent proponent of cost-benefit analysis, has called the existing state of affairs "statistical murder." 25

From this perspective, cost-benefit analysis emerges as both a money-saver and a life-saver. By subjecting regulations to a costbenefit test, we would not only stop spending hundreds of millions or billions of dollars to save a single life, we could also take that money and spend it on saving even more lives through different life-saving measures.

That, at least, is the theory. We will argue in the following Sections that there are good reasons to question both the theory and the facts it rests on. Nevertheless, the notion that the current system produces crazy, even deadly, rules, and that better economic analysis

${ }^{22}$ See John F. Morrall III, A Review of the Record, REgulation, Nov.-Dec. 1986, at 25, 30 tbl.4, relied upon in, among others, STEPHEN BREYER, BREAKING THE VICIOUS Circle: TOWARD EFFective RISK REgulation (1993); W. KIP Viscusi, Fatal TRADEOFFS: PUBliC AND PRIVATE RESPONSIBILITIES FOR RISK 264 tbl.14-5 (1992); OfFICE OF MGMT. \& Budget, Regulatory Program of THE United States GovernMENT, APRIL 1, 1991-MARCH 31, 1992 (1991); and Kenneth J. Arrow et al., Is There a Role for Benefit-Cost Analysis in Environmental, Health, and Safety Regulation?, 272 SCIENCE 221 (1996).

${ }^{23}$ Tammy $O$. Tengs et al., Five-Hundred Life-Saving Interventions and Their CostEffectiveness, 15 RiSK ANALYSIS 369, 377 app. A (1995). For a critique of this study, see Lisa Heinzerling \& Frank Ackerman, The Humbugs of the Anti-Regulatory Movement, 87 CORNELL L. REV. 648, 650-61 (2002).

${ }^{24}$ Tammy O. Tengs \& John D. Graham, The Opportunity Costs of Haphazard Social Investments in Life-Saving, in RISKS, COSTS, AND LIVES SAVED: GETTING BETTER RESULTS FROM REGULATION 167, 172 (Robert W. Hahn ed., 1996).

${ }^{25}$ Risk Assessment and Cost-Benefit Analysis: Hearing Before the House Comm. on Sci., 104th Cong. 71 (1995) (statement of John D. Graham, Head of the Office of Information and Regulatory Affairs). 
would avert this terrible result, remains one of the most persistent arguments offered on behalf of cost-benefit analysis.

\section{B. Objectivity and Transparency}

A second important set of arguments holds that cost-benefit analysis would produce a better regulatory process-one that is more objective and more transparent, and thus more accountable to the public.

The holy grail of administrative law is agency decision making based on objective standards. The idea is to prevent an agency either from making arbitrary decisions or, more invidiously, from benefiting politically-favored groups through its decisions. Cost-benefit analysis has been offered as a means of constraining agency discretion in this way.

Another important goal, said to be promoted by cost-benefit analysis, is the transparency of administrative procedures. Decisions about environmental protection are notoriously complex. They reflect the input of biologists, toxicologists, epidemiologists, economists, engineers, lawyers, and other experts whose work is complicated and arcane. The technical details of these decisions often conceal crucial judgments about how much scientific uncertainty is too much, which human populations should be protected from illness and even death, and how important the future is relative to the present.

In order for the public to be part of the process of decision making about the environment, these judgments must be offered and debated in language accessible to people who are not biologists, toxicologists, or other kinds of experts. Many advocates of cost-benefit analysis believe that their methodology provides such a language. Relatedly, they assert that cost-benefit analysis renders decision making transparent insofar as it requires decision makers to reveal all of the assumptions and uncertainties reflected in their decisions.

\section{FUNDAMENTAL FLAWS}

As we have seen, cost-benefit analysis involves the creation of artificial markets for things-like good health, long life, and clean airthat are not bought and sold. It also involves the devaluation of future events through discounting.

So described, the mindset of the cost-benefit analyst is likely to seem quite foreign. The translation of all good things into dollars and the devaluation of the future are inconsistent with the way many people view the world. Most of us believe that money doesn't buy happi- 
ness. Most religions tell us that every human life is sacred; it is obviously illegal, as well as immoral, to buy and sell human lives. Most parents tell their children to eat their vegetables and do their homework, even though the rewards of these onerous activities lie far in the future. Monetizing human lives and discounting future benefits seem at odds with these common perspectives.

The cost-benefit approach also is inconsistent with the way many of us make daily decisions. Imagine performing a new cost-benefit analysis to decide whether to get up and go to work every morning, whether to exercise or eat right on any given day, whether to wash the dishes or leave them in the sink, and so on. Inaction would win far too often-and an absurd amount of effort would be spent on analysis. Most people have long-run goals, commitments, and habits that make such daily balancing exercises either redundant or counterproductive. The same might be true of society as a whole undertaking individual steps in the pursuit of any goal, set for the long haul, that cannot be reached overnight-including, for example, the achievement of a clean environment.

Moving beyond these intuitive responses, we offer in this Section a detailed explanation of why cost-benefit analysis of environmental protection fails to live up to the hopes and claims of its advocates. There is no quick fix, because these failures are intrinsic to the methodology, appearing whenever it is applied to any complex environmental problem. In our view, cost-benefit analysis suffers from four fundamental flaws, addressed in the next four Sections:

- the standard economic approaches to valuation are inaccurate and implausible;

- the use of discounting improperly trivializes future harms and the irreversibility of some environmental problems;

- the reliance on aggregate, monetized benefits excludes questions of fairness and morality; and

- the value-laden and complex cost-benefit process is neither objective nor transparent.

\section{A. Dollars Without Sense}

Recall that cost-benefit analysis requires the creation of artificial prices for all relevant health and environmental impacts. To weigh the benefits of regulation against the costs, we need to know the monetary value of preventing the extinction of species, preserving many different ecosystems, avoiding all manner of serious health im- 
pacts, and even saving human lives. Without such numbers, costbenefit analysis cannot be conducted.

Artificial prices have been estimated for many, though by no means all, benefits of regulation. As discussed, preventing the extinction of bald eagles reportedly goes for somewhat more than $\$ 250$ per household. Preventing retardation due to childhood lead poisoning comes in at about $\$ 9000$ per lost IQ point in the standard view, or as low as $\$ 1100$ per point in Lutter's alternative. Saving a life is ostensibly worth $\$ 6.3$ million.

This quantitative precision, achieved through a variety of indirect techniques for valuation, comes at the expense of accuracy and sometimes, common sense. Though problems arise in many areas of valuation, we will focus primarily on the efforts to attach a monetary value to human life, both because of its importance in cost-benefit analysis and because of its glaring contradictions.

We note, however, that the same kind of problems we are about to discuss affect other valuation issues raised by cost-benefit analysis, such as estimating the value of clean water, biodiversity, or entire ecosystems. The upshot is that cost-benefit analysis is fundamentally incapable of delivering on its promise of more economically efficient decisions about protecting human life, health, and the environment. Absent a credible monetary metric for calculating the benefits of regulation, cost-benefit analysis is inherently unreliable.

\section{There Are No "Statistical" People}

What can it mean to say that saving one life is worth $\$ 6.3$ million? Human life is the ultimate example of a value that is not a commodity and does not have a price. You cannot buy the right to kill someone for $\$ 6.3$ million, nor for any other price. Most systems of ethical and religious belief maintain that every life is sacred. If analysts calculated the value of life itself by asking people what it is worth to them (the most common method of valuation of other environmental benefits), the answer would be infinite, as "no finite amount of money could compensate a person for the loss of his life, simply because money is no good to him when he is dead. ${ }^{26}$

The standard response is that a value like $\$ 6.3$ million is not actually a price on an individual's life or death. Rather, it is a way of expressing the value of small risks of death; for example, it is one million

\footnotetext{
${ }^{26}$ John Broome, Trying to Value a Life, 9 J. PUB. ECON. 91, 92 (1978).
} 
times the value of a one in a million risk. If people are willing to pay $\$ 6.30$ to avoid a one in a million increase in the risk of death, then the "value of a statistical life" is $\$ 6.3$ million. ${ }^{27}$

Unfortunately, this explanation fails to resolve the dilemma. It is true that risk (or "statistical life") and life itself are distinct concepts. In practice, however, analysts often ignore the distinction between valuing risk and valuing life. ${ }^{28}$ Many regulations reduce risk for a large number of people and avoid actual death for a much smaller number. A complete cost-benefit analysis should, therefore, include valuation of both of these benefits. However, the standard practice is to calculate a value only for "statistical" life and to ignore life itself.

The confusion between the valuation of risk and the valuation of life itself is embedded in current regulatory practice in another way as well. The Office of Management and Budget, which reviews costbenefit analyses prepared by federal agencies pursuant to executive order, instructs agencies to discount the benefits of life-saving regulations from the moment of avoided death, rather than from the time when the risk of death is reduced. ${ }^{29}$ This approach to discounting is plainly inconsistent with the claim that cost-benefit analysis seeks to evaluate risk. When a life-threatening disease, such as cancer, has a long latency period, many years may pass between the time when a risk is imposed and the time of death. If monetary valuations of statistical life represented risk, instead of life, then the value of statistical life would be discounted from the date of a change in risk (typically, when a new regulation is enforced) rather than from the much later date of avoided actual death. ${ }^{30}$

In acknowledging the monetary value of reducing risk, economic analysts have contributed to our growing awareness that lifethreatening risk itself-and not just the end result of such risk, death-is an injury. But they have blurred the line between risks and actual deaths, by calculating the value of reduced risk while pretending that they have produced a valuation of life itself. The paradox of

${ }^{27}$ E.g., VISCUSI, supra note 1 , at 46.

${ }^{28}$ For further elaboration, see Lisa Heinzerling, The Rights of Statistical People, 24 HARV. ENVTL. L. REV. 189, 203-06 (2000), arguing that many analysts treat the valuation of risk as equivalent to a valuation of life without calculating the value of life.

${ }^{29}$ ADM'R OF THE OFFICE OF INFO. \& REgULATORY AFFAIRS, OFFICE OF MGMT. \& BUDGET, ECONOMIC ANALYSIS OF FEDERAL REGULATIONS UNDER EXECUTTVE ORDER 12,866, at pt. III.B.5(a) (Jan. 11, 1996), http://www.whitehouse.gov/omb/inforeg/ riaguide.html.

${ }^{30}$ Lisa Heinzerling, Discounting Life, 108 YALE L.J. 1911, 1913 (1999); Lisa Heinzerling, Discounting Our Future, 34 LAND \& WATER L. REV. 39, 71 (1999). 
monetizing the infinite or immeasurable value of human life has not been resolved; it only has been glossed over.

\section{People Care About Other People}

Another large problem with the standard approach to valuation of life is that it asks individuals (either directly through surveys or indirectly through observing wage and job choices) only about their attitudes toward risks to themselves.

A recurring theme in literature suggests that our deepest and noblest sentiments involve valuing someone else's life more highly than our own: think of parents' devotion to their children, soldiers' commitment to those whom they are protecting, lovers' concern for each other. Most spiritual beliefs call on us to value the lives of others-not only those closest to us, but also those whom we have never met.

This point echoes a procedure that has become familiar in other areas of environmental valuation. Economists often ask about existence values: how much is the existence of a wilderness area or an endangered species worth to you, even if you never will experience it personally? If this question makes sense for bald eagles and national parks, it must be at least as important when applied to safe drinking water and working conditions for people we don't know.

What is the existence value of a person you will never meet? How much is it worth to you to prevent a death far away? The answer cannot be deduced solely from your attitudes toward risks to yourself. We are not aware of any attempts to quantify the existence value of the life of a stranger, let alone a relative or a friend, but we are sure that most belief systems affirm that this value is substantial (assuming, of course, that the value of life is a number in the first place).

\section{Voting Is Different from Buying}

Cost-benefit analysis, which relies on estimates of individuals' preferences as consumers, also fails to address the collective choice presented to society by most public health and environmental problems.

Valuation of environmental benefits is based on individuals' private decisions as consumers or workers, not on their public values as citizens. However, policies that protect the environment are often public goods and are not available for purchase in individual portions. In a classic example of this distinction, the philosopher Mark Sagoff found that his students, in their role as citizens, opposed commercial 
ski development in a nearby wilderness area, but, in their role as consumers, would plan to go skiing there if the development were built. ${ }^{31}$ There is no contradiction between these two views: as individual consumers, the students would have no way to express their collective preference for wilderness preservation. Their individual willingness to pay for skiing would send a misleading signal about their views as citizens.

It is often impossible to arrive at a meaningful social valuation by adding up the willingness to pay expressed by individuals. What could it mean to ask how much you are personally willing to pay to clean up a major oil spill? If no one else contributes, the clean-up will not happen regardless of your decision. As the Nobel Prize-winning economist Amartya Sen has pointed out, if your willingness to pay for a large-scale public initiative is independent of what others are paying, then you probably have not understood the nature of the problem. ${ }^{32}$ Instead, a collective decision about collective resources is required.

In a similar vein, the philosopher Henry Richardson argues that reliance on the cost-benefit standard forecloses the process of democratic deliberation that is necessary for intelligent decision making. In his view, attempts to make decisions based on monetary valuation of benefits freeze preferences in advance, leaving no room for the changes in response to new information, rethinking of the issues, and negotiated compromises that lie at the heart of the deliberative process.

Cost-benefit analysis turns public citizens into selfish consumers and interconnected communities into atomized individuals. In this way, it distorts the question it sets out to answer-how much do we, as a society, value health and the environment?

\section{Numbers Don't Tell Us Everything}

A few simple examples illustrate that numerically equal risks are not always equally deserving of regulatory response. The death rate is

${ }^{31}$ Mark SAgoff, The ECONOMY OF THE EARTH: PHILOSOPHY, LAW, AND THE ENVIRONMENT 50-53 (1988).

${ }^{32}$ See Amartya Sen, The Discipline of Cost-Benefit Analysis, 29 J. LEGAL STUD. 931, 949 (2000) ("The 'lone ranger' model of environmental evaluation . . . confounds the nature of the problem at hand.").

${ }^{33}$ Henry S. Richardson, The Stupidity of the Cost-Benefit Standard, 29 J. LEGAL STUD. 971, 986-89 (2000). On the importance of allowing preference change in response to deliberation, see also Cass R. Sunstein, Preferences and Politics, 20 PHIL. \& PUB. AFF. 3 (1991). 
roughly the same (somewhat less than one in a million) from a day of downhill skiing, from a day of working in the construction industry, or from drinking about twenty liters of water containing fifty parts per billion of arsenic - the old regulatory limit that was recently revised by the EPA. ${ }^{34}$ This does not mean that society's responsibility to reduce risks is the same in each case.

Most people view risks imposed by others, without an individual's consent, as more worthy of government intervention than risks that an individual knowingly accepts. On that basis, the highest priority among our three examples is to reduce drinking water contamination-a hazard to which no one has consented. The acceptance of a risky occupation such as construction is at best quasi-voluntary; it involves somewhat more individual discretion than the "choice" of public drinking water supplies even though many people go to work under great economic pressure and with little information about occupational hazards. In contrast, the choice of risky recreational pursuits such as skiing is entirely discretionary; obviously, no one is forced to ski. Safety regulation in construction work is thus more urgent than regulation of skiing, despite the equality of numerical risk.

In short, even for ultimate values such as life and death, the social context is decisive in our evaluation of risks. Cost-benefit analysis assumes the existence of generic, acontextual risk and thereby ignores the contextual information that determines the manner in which many people, in practice, think about real risks to real people.

${ }^{34}$ Skiing: in 1999 there were 30 fatalities and 52.2 million skier/snowboarder visits to ski slopes, for a death rate of 0.57 per million skier-days. National Ski Areas Association, Facts About Skiing/Snowboarding, at http://www.nsaa.org/safety/facts_about.asp.

Constmuction: in 1997 there were 14.1 fatal injuries per 100,000 full-time construction workers. NAT'L INST. FOR OCCUPATIONAL SAFETY \& HEALTH, WORKER HEALTH CHARTBOOK, 2000, at 36 (2000), available at http://www.cdc.gov/niosh/ $00-127 \mathrm{pd} . \mathrm{html}$. Assuming 250 days per full-time year, the death rate was 0.56 per million days of work.

Arsenic: male lifetime cancer rates per ppb of arsenic are $2.53 \times 10^{-5}$ for bladder cancer and $2.75 \times 10^{-5}$ for lung cancer. EPA, ARSENIC STUDY, supra note 20, at B-8 exh.2. (Female cancer rates are higher.) Death rates are $26 \%$ for bladder cancer and $88 \%$ for lung cancer, for a combined male mortality rate of $3.08 \times 10^{-5}$ per lifetime ppb of arsenic. Id.

The EPA analysis is based on a person who drinks 2 liters of water per day. $I d$. at B-5. So lifetime consumption over 70 years is $2 \times 70 \times 365$, which equals $5.11 \times 10^{4}$ liters. If risk is proportional to arsenic consumption, the risk per ppb per liter is $(3.08 \times$ $\left.10^{-5}\right) /\left(5.11 \times 10^{4}\right)$, which equals $6.03 \times 10^{-10}$ per ppb per liter, or $3.01 \times 10^{-8}$ per liter of $50 \mathrm{ppb}$ water. At that rate, the risk of death from drinking 19 liters of $50 \mathrm{ppb}$ water equals $19 \times\left(3.01 \times 10^{-8}\right)$, which is 0.57 in a million. 


\section{Artificial Prices Are Expensive}

Finally, the economic valuation called for by cost-benefit analysis is fundamentally flawed because it demands an enormous volume of consistently updated information, which is beyond the practical capacity of our society to generate.

All attempts at valuation of the environment begin with a problem: the goal is to assign monetary prices to things that have no prices because they are not for sale. One of the great strengths of the market is that it provides so much information about real prices. For any commodity that actually is bought and sold, prices are communicated automatically, almost costlessly, and with constant updates as needed. To create artificial prices for environmental values, economists have to find some way to mimic the operation of the market. Unfortunately, the process is far from automatic, certainly not costless, and has to be repeated every time an updated price is needed.

As a result, there is constant pressure to use outdated or inappropriate valuations. Indeed, there are sound economic reasons for doing so: no one can afford constant updates, and significant savings can be achieved by using valuations created for other cases. In the EPA's original cost-benefit analysis of a revised standard for arsenic in drinking water, a valuation estimated for a case of chronic bronchitis, taken from a study performed ten years earlier, was used to represent the value of a case of nonfatal bladder cancer. ${ }^{35}$

This is not, we hope and believe, because anyone thinks that bronchitis and bladder cancer are the same disease. The reason is more mundane: no one has performed an analysis of the cost of bladder cancer, and even the extensive analysis of arsenic regulations did not include enough time and money to do so. Therefore, the investigators used an estimated value for a very different disease. The only explanation offered for this procedure was that it had been done before, and the investigators thought nothing better was available. ${ }^{36}$

Use of the bronchitis valuation to represent bladder cancer can charitably be described as "grasping at straws." Lacking the time and money to fill in the blank carefully, the economists simply picked a number. This is not remotely close to the level of rigor that is seen throughout the natural science, engineering, and public health portions of the arsenic analysis, yet it will happen again for exactly the

\footnotetext{
${ }^{35}$ EPA, ARSENIC STUDY, supra note 20, at 5-24 (citation omitted).

${ }^{36}$ Id.
} 
same reason. It is not a failure of will or intellect, but rather the inescapable limitations of time and budget that lead to reliance on dated, inappropriate, and incomplete information to fill in the gaps on the benefit side of a cost-benefit analysis.

\section{B. Trivializing the Future}

One of the great triumphs of environmental law is its focus on the future: it seeks to avert harms to people and to natural resources in the future, not only within this generation, but within future generations as well. Indeed, one of the primary objectives of the National Environmental Policy Act, which has been called our basic charter of environmental protection, is to nudge the nation into "fulfill[ing] the responsibilities of each generation as trustee of the environment for succeeding generations."

Protection of endangered species and ecosystems, reduction of pollution from persistent chemicals such as dioxin and DDT, prevention of long-latency diseases such as cancer, protection of the unborn against the health hazards from exposure to toxins in the womb-all of these protections are afforded by environmental law, and all of them look to the future as well as to the present. Environmental law seeks, moreover, to avoid the unpleasant surprises that come with discontinuities and irreversibility-the kinds of events that outstrip our powers of quantitative prediction. Here too, environmental law tries to protect the future in addition to the present.

Cost-benefit analysis systematically downgrades the importance of the future in two ways: through the technique of discounting and through predictive methodologies that take inadequate account of the possibility of catastrophic and irreversible events.

The most common, and commonsense, argument in favor of discounting future human lives saved, illnesses averted, and ecological disasters prevented, is that it is better to suffer a harm later rather than sooner. What's wrong with this argument? A lot, as it turns out.

\section{Do Future Generations Count?}

The first problem with the later-is-better argument for discounting is that it assumes that one person is deciding between dying or falling ill now, or dying or falling ill later. In that case, virtually everyone would prefer later. But many environmental programs protect the far

${ }^{37} 42$ U.S.C. $\$ 4331$ (b) (1) (1994). 
future, beyond the lifetime of today's decision makers. Thus, the choice implicit in discounting is between preventing harms to the current generation and preventing similar harms to future generations. Seen in this way, discounting looks like a fancy justification for foisting our problems off onto the people who come after us.

The time periods involved in protecting the environment are often enormous-many decades for a wide range of problems, and even many centuries, in the case of climate change, radioactive waste, and other persistent toxins. With time spans this long, discounting at any positive rate will make even global catastrophes seem trivial. At a discount rate of five percent, for example, the death of a billion people 500 years from now becomes less serious than the death of one person today. $^{38}$

\section{Does Haste Prevent Waste?}

The justification for discounting often assumes that environmental problems will not get any worse if we wait to address them. In the market paradigm, buying environmental protection is just like buying any other commodity. You can buy a new computer now or later, and if you don't need it this year, you should probably wait. The technology will undoubtedly keep improving, so next year's models will do more yet cost less. An exactly parallel argument has been made about climate change (and other environmental problems) by some economists: if we wait for further technological progress, we will get more for our climate change mitigation dollars in the future.

If environmental protection were mass produced by the computer industry, and if environmental problems would agree to stand still indefinitely and wait for us to respond, this might be a reasonable approach. In the real world, however, it is a ludicrous and dangerous strategy.

Too many years of delay might mean that the polar ice cap melts, the spent uranium leaks out of the containment ponds, the hazardous waste seeps into groundwater and basements and backyards-at which point we cannot put the genie back in the bottle at any reasonable cost (or perhaps not at all).

Environmentalists often talk of potential "crises"-threats that

${ }^{38}$ The general formula for calculating the present value of a benefit of $X$ to be received $N$ years from now when the discount rate is $r$ is: $X /(1+r)^{N}$. WILLIAM J. Baumol \& Alan S. Blinder, Economics: Principles and Policy 386-87 (6th ed. 1994). The example in the text comes from Derek Parfit, Rfasons And Persons 357 (1984). 
problems will become suddenly and irreversibly worse. In response to such threats, environmentalists and some governments advocate the so-called "precautionary principle," which calls upon regulators to err on the side of caution and protection when risks are uncertain. Costbenefit analysts, for the most part, do not assume the possibility of crisis. Their world view assumes stable problems, with control costs that are stable or declining over time, and thus finds precautionary investment in environmental protection to be a needless expense. Discounting is part of this noncrisis perspective. By implying that the present cost of future environmental harms declines, lockstep, with every year that we look ahead, discounting ignores the possibility of catastrophic and irreversible harms.

For this very reason, some prominent economists have rejected the discounting of intangibles. As William Baumol wrote in an important early article on discounting the benefits of public projects:

There are important externalities and investments of the public goods variety which cry for special attention. Irreversibilities constitute a prime example. If we poison our soil so that never again will it be the same, if we destroy the Grand Canyon and turn it into a hydroelectric plant, we give up assets which like Goldsmith's bold peasantry, “ . . their country's pride, when once destroy'd can never be supplied." All the wealth and resources of future generations will not suffice to restore them.

Most cost-benefit analysts do not exhibit this kind of humility about what the future might hold in store for us.

\section{Begging the Question}

Extensive discounting of future environmental problems lies at the heart of many recent reviews of regulatory costs and benefits that charge "statistical murder." When the costs and benefits of environmental protection are compared to those of safety rules (like requiring fire extinguishers for airplanes) or medical procedures (like vaccinating children against disease), environmental protection almost always comes out the loser. Why is this so? ${ }^{40}$

These studies all discount future environmental benefits by at least five percent per year. This has little effect on the evaluation of (1968).

${ }^{39}$ William J. Baumol, On the Social Rate of Discount, 58 Am. ECON. REv. 788, 801

40 This discussion draws from Lisa Heinzerling, Regulatory Costs of Mythic Proportions, 107 YALE L.J. 1981 (1998); Lisa Heinzerling, Five-Hundred Life-Saving Interventions and Their Misuse in the Debate Over Regulatory Reform, RISK (forthcoming 2002); and Heinzerling \& Ackerman, supra note 23. 
programs-like auto safety rules requiring seat belts and fire safety rules requiring smoke alarms-that could start saving lives right away. However, for environmental programs like hazardous waste cleanups and control of persistent toxins that save lives in the future, discounting matters a great deal. Especially since, as explained above, the benefits are assumed to occur in the future when deaths are avoided, rather than in the near term when risks are reduced.

By using discounting, analysts assume the answer to the question they purport to address. That is, which programs are most worthwhile? The researchers begin with premises that guarantee that programs designed for the long haul (like environmental protection) are not as important as programs that look to the shorter term. When repeated without discounting (or with benefits assumed to occur when risks are reduced), these studies support many more environmental programs, and the cry of "statistical murder" rings hollow.

\section{Citizens and Consumers-Reprise}

The issue of discounting illustrates once again the failure of costbenefit analysis to take into account the difference between citizens and consumers. Many people advocate discounting on the ground that it reflects people's preferences, as expressed in market decisions concerning risk. But again, this omits the possibility that people will have different preferences when they take on a different role. The future seems to matter much more to American citizens than to American consumers, even though they are of course the same people.

For example, Americans are notoriously bad at saving money on their own, apparently expressing a disinterest in the future. Still, Social Security is arguably the most popular entitlement program in the United States. The tension between Americans' personal saving habits and their enthusiasm for Social Security implies a sharp divergence between the temporal preferences of people as consumers and as citizens. Thus, private preferences for current over future consumption should not be used to subvert public judgments that future harms are as important as immediate ones.

\section{Exacerbating Inequality}

The third fundamental defect of cost-benefit analysis is that it tends to ignore, and therefore has the effect of reinforcing, patterns of economic and social inequality. Cost-benefit analysis consists of adding up all the costs of a policy, adding up all the benefits, and 
comparing the totals. Implicit in this innocuous-sounding procedure is the controversial assumption that it does not matter who gets the benefits and who pays the costs. Both benefits and costs are measured simply as dollar totals; those totals are silent on questions of equity and distribution of resources.

In our society, concerns about equity frequently do, and should, enter into debates over public policy. There is an important difference between spending state tax revenues to improve the parks in rich communities and spending the same revenues to clean up pollution in poor communities. The value of these two initiatives, measured using cost-benefit analysis, might be the same in both cases, but this does not mean that the two policies are equally urgent or desirable.

The problem of equity runs even deeper. Benefits are typically measured by willingness to pay for environmental improvement, and the rich are able and willing to pay for more than the poor. Imagine a cost-benefit analysis of siting an undesirable facility, such as a landfill or incinerator. Wealthy communities are willing to pay more for the benefit of not having the facility in their backyards; thus, the net benefits to society as a whole will be maximized by putting the facility in a low-income area. (Note that wealthy communities do not actually have to pay for the benefit of avoiding the facility; the analysis depends only on the fact that they are willing to pay.)

This kind of logic was made (in)famous in a 1991 memo circulated by Lawrence Summers (former Secretary of the Treasury and current President of Harvard University) when he was the chief economist at the World Bank. Discussing the migration of "dirty industries" to developing countries, Summers' memo explained:

The measurements of the costs of health impairing pollution depend[] on the foregone earnings from increased morbidity and mortality. From this point of view a given amount of health impairing pollution should be done in the country with the lowest cost, which will be the country with the lowest wages. I think the economic logic behind dumping a load of toxic waste in the lowest wage country is impeccable and we should face up to that. ${ }^{41}$

After this memo became public, Brazil's then-Secretary of the Environment Jose Lutzenburger wrote to Summers:

Your reasoning is perfectly logical but totally insane... Your thoughts

${ }^{41}$ Memorandum from Lawrence H. Summers, Chief Economist, World Bank to Distribution (Dec. 12, 1991), http://www.whirledbank.org/ourwords/summers.html [hereinafter Summers Memo]. 
[provide] a concrete example of the unbelievable alienation, reductionist thinking, social ruthlessness and the arrogant ignorance of many conventional "economists" concerning the nature of the world we live in."

If decisions are based strictly on cost-benefit analysis and willingness to pay, most environmental burdens will end up being imposed on the countries, communities, and individuals with the least resources. This theoretical pattern bears an uncomfortably close resemblance to reality. Cost-benefit methods should not be blamed for existing patterns of environmental injustice; we suspect that pollution is typically dumped on the poor without waiting for formal analysis. Still, cost-benefit analysis rationalizes and reinforces the problem, allowing environmental burdens to flow downhill along the income gradients of an unequal world. It is hard to see this as part of an economically optimal or politically objective method of decision making.

In short, equity is an important criterion for evaluation of public policy, but it does not fit into the cost-benefit framework. The same is true of questions of rights and morality principles that are not reducible to monetary terms. Calculations that are acceptable, even commonsense, for financial matters can prove absurd or objectionable when applied to moral issues, as shown by the following example.

A financial investment with benefits worth five times its costs would seem like an obviously attractive bargain. Compare this to the estimates that front airbags on the passenger side of automobiles may cause one death, usually of a child, for every five lives saved. If we really believed that lives-even statistical lives-were worth $\$ 6$ million, or any other finite dollar amount, then endorsing the airbags should be no more complicated than accepting the financial investment. However, many people do find the airbag tradeoff troubling or unacceptable, implying that there is a different, nonquantitative value of a life that is at stake here. If a public policy brought some people five dollars of benefits for every one dollar it cost to others, the winners could in theory compensate the losers. No such compensation is possible if winning and losing are measured in deaths rather than dollars. $^{43}$

In comparing the deaths of adults prevented by airbags with the deaths of children caused by airbags, or in exploring countless other

${ }^{42}$ Postscript to Summers Memo, supra note 41 (ellipsis in original).

43 See Fred KuChLER \& Elise Golan, U.S. DEP'T OF AGRIC., ASSIGNING VAlues to LifE: COMPARING METHODS FOR VAluING HEAlth RISKS 52 (Agric. Econ. Report No. 784,1999 ) ("[I]t is difficult to argue that a life lost in one group can be offset one-forone by a life saved in another group."). 
harms that might be mitigated through regulation, the real debate is not between rival cost-benefit analyses. Rather, it is between environmental advocates who frame the issue as a matter of rights and ethics, and others who see it as an acceptable area for economic calculation. That debate is inescapable, and it logically comes before the details of evaluating costs and benefits.

\section{Less Objectivity and Transparency}

A fourth fundamental flaw of cost-benefit analysis is that it is unable to deliver on the promise of more objective and more transparent decision making. In fact, in most cases the use of cost-benefit analysis is likely to deliver less objectivity and less transparency.

For the reasons we have discussed, there is nothing objective about the basic premises of cost-benefit analysis. Treating individuals solely as consumers, rather than as citizens with a sense of moral responsibility to the larger society, represents a distinct and highly contestable world view. Likewise, the use of discounting reflects judgments about the nature of environmental risks and citizens' responsibilities toward future generations that are, at a minimum, debatable. Because value-laden premises permeate cost-benefit analysis, the claim that cost-benefit analysis offers an "objective" way to make government decisions is simply bogus.

Furthermore, as we have seen, cost-benefit analysis relies on a byzantine array of approximations, simplifications, and counterfactual hypotheses. Thus, the actual use of cost-benefit analysis inevitably involves countless judgment calls. People with strong, and clashing, partisan positions naturally will advocate that discretion in the application of this methodology be exercised in favor of their positions, further undermining the claim that cost-benefit analysis is objective.

Perhaps the best way to illustrate how little economic analysis has to contribute, objectively, to the fundamental question of how clean and safe we want our environment to be is to refer again to the controversy over cost-benefit analysis of the EPA's regulation of arsenic in drinking water. As Cass Sunstein has recently argued, the available information on the benefits of arsenic reduction supports estimates of net benefits from regulation ranging from less than zero up to $\$ 560$ million or more. ${ }^{44}$ The number of deaths avoided annually by regula-

${ }^{44}$ Cass R. Sunstein, The Arithmetic of Arsenic, 90 GEO. L.J. (forthcoming 2002). 
tion is, according to Sunstein, between zero and $112 .^{45}$ A procedure that allows such an enormous range of different evaluations of a single rule is certainly not the objective, transparent decision rule that its advocates have advertised.

These uncertainties arise from the limited knowledge of the epidemiology and toxicology of exposure to arsenic as well as the controversial series of assumptions required for valuation and discounting of costs and (particularly) benefits. As Sunstein explains, a number of different positions, including most of those heard in the recent controversy over arsenic regulation, could be supported by one or another reading of the evidence. ${ }^{40}$

Some analysts might respond that this enormous range of outcomes is not possible if the proper economic assumptions are usedif, for example, human lives are valued at $\$ 6$ million apiece and discounted at a five percent yearly rate (or, depending on the analyst, other favorite numbers). But these assumptions beg fundamental questions about ethics and equity, and one cannot decide whether to embrace them without thinking through the whole range of moral issues they raise. Yet once one has thought through these issues, there is no need then to collapse the complex moral inquiry into a series of numbers. Pricing the priceless merely translates our inquiry into a different, and foreign, language-one with a painfully impoverished vocabulary.

For many of the same reasons, cost-benefit analysis also generally fails to achieve the goal of transparency. Cost-benefit analysis is a complex, resource-intensive, and expert-driven process. It requires a great deal of time and effort to attempt to unpack even the simplest cost-benefit analysis. Few community groups, for example, have access to the kind of scientific and technical expertise that would allow them to evaluate whether, intentionally or unintentionally, the authors of a cost-benefit analysis have unfairly slighted the interests of the community or some of its members. Few members of the public can participate meaningfully in the debates about the use of particular regression analyses or discount rates which are central to the cost-

${ }^{45}$ Id.

${ }^{46}$ Id. Given this enormous range of uncertainty, it is hard to understand Sunstein's belief (expressed in the same article) that cost-benefit analysis is still useful for screening regulatory options. This could be true only if a significant number of serious proposals had costs that were many orders of magnitude greater than their benefits. As we have discussed, this is a widely held, but empirically false, view of environmental regulation. 
benefit method.

The translation of lives, health, and nature into dollars also renders decision making about the underlying social values less rather than more transparent. As we have discussed, all of the various steps required to reduce a human life to a dollar value are open to debate and subject to uncertainty. However, the specific dollar values kicked out by cost-benefit analysis tend to obscure these underlying issues rather than encourage full public debate about them.

\section{Practical Problems}

The last Part showed that there are deep, inherent problems with cost-benefit analysis. In practice, these problems only get worse; leading examples of cost-benefit analysis fall far short of the theoretical ideal. The continuing existence of these practical problems further undercuts the utility and wisdom of using cost-benefit analysis to evaluate environmental policy.

\section{A. The Limits of Quantification}

Cost-benefit studies of regulations focus on quantified benefits of the proposed action and generally ignore other, nonquantified, health and environmental benefits. This raises a serious problem because many benefits of environmental programs-including the prevention of many nonfatal diseases and harms to the ecosystem-either have not been quantified or are not capable of being quantified at this time. Indeed, for many environmental regulations, the only benefit that can be quantified is the prevention of cancer deaths. On the other hand, one can virtually always come up with some number for the costs of environmental regulations. Thus, in practice, cost-benefit analysis tends to skew decision making against protecting public health and the environment.

For example, regulation of workers' exposure to formaldehyde is often presented as the extreme of inefficiency, supposedly costing $\$ 72$ billion per life saved. ${ }^{47}$ This figure is based on the finding that the regulation prevents cancers that occur only in small numbers, but which have been thoroughly evaluated in numerical terms. But the formaldehyde regulation also prevents many painful but nonfatal illnesses excluded from the $\$ 72$ billion figure. If described solely as a means of reducing cancer, the regulation indeed would be very ex-

\footnotetext{
${ }^{47}$ Morrall, supra note 22, at 25, 30 tbl.4.
} 
pensive. But if described as a means of reducing cancer and other diseases, the regulation would make a good deal of sense. Workplace regulation of formaldehyde is not a bad answer, but it does happen to be an answer to a different question.

The formaldehyde case is by no means unique. Often, the only regulatory benefit that can be quantified is the prevention of cancer, yet cancer has a latency period of between five and forty years. When discounted at five percent, a cancer death forty years from now has a "present value" of only one-seventh of a death today. Thus, one of the benefits that most often can be quantified-allowing it to be folded into cost-benefit analysis-is also one that is heavily discounted, making the benefits of preventive regulation seem trivial.

\section{B. Ignoring What Cannot Be Counted}

A related practical problem is that even when the existence of unquantified or unquantifiable benefits is recognized, their importance is frequently ignored. Many advocates of cost-benefit analysis concede that the decision-making process must make some room for nonquantitative considerations. Some environmental benefits never have been subjected to rigorous economic evaluation. Other important considerations in environmental protection (such as the fairness of the distribution of environmental risks) cannot be quantified and priced.

In practice, however, this kind of judgment is often forgotten, or even denigrated, once all the numbers have been crunched. No matter how many times the EPA, for example, says that one of its rules will produce many benefits-like the prevention of illness or the protection of ecosystems-that cannot be quantified, the non-quantitative aspects of its analyses are almost invariably ignored in public discussions of its policies.

When the Clinton administration's EPA proposed, for example, strengthening the standard for arsenic in drinking water, it cited many human illnesses that would be prevented by the new standard but that could not be expressed in numerical terms. ${ }^{48}$ Subsequent public discussion of the EPA's cost-benefit analysis of this standard, however, inevitably referred only to the EPA's numerical analysis and forgot

${ }^{48}$ National Primary Drinking Water Regulations; Arsenic and Clarifications to Compliance and New Source Contaminants Monitoring, 66 Fed. Reg. 6976, 7000-13, (proposed Jan. 22, 2001) (to be codified at 40 C.F.R. pts. 9, 141, 142). 
about the cases of avoided illness that could not be quantified. ${ }^{49}$

\section{Overstated Costs}

There is also a tendency, as a matter of practice, to overestimate the costs of regulations in advance of their implementation. This happens in part because regulations often encourage new technologies and more efficient ways of doing business; these innovations reduce the cost of compliance. It is also important to keep in mind, when reviewing cost estimates, that they are usually provided by the regulated industry itself, which has an obvious incentive to offer high estimates of costs as a way of warding off new regulatory requirements.

One study found that costs estimated in advance of regulation were more than twice the actual costs in eleven out of twelve cases. Another study found that advance total cost estimates were more than $25 \%$ higher than actual costs for fourteen out of twenty-eight regulations; advance estimates were more than $25 \%$ too low in only three of the twenty-eight cases. ${ }^{51}$ Before the 1990 Clean Air Act Amendments ${ }^{52}$ took effect, industry anticipated that the cost of sulfur reduction under the amendments would be $\$ 1500$ per ton..$^{53}$ In 2000 , the actual cost was under $\$ 150$ per ton. ${ }^{54}$ Of course, not all cost-benefit analyses overstate the actual costs of regulation, but given the technologyforcing character of environmental regulations, it is not surprising to find a marked propensity to overestimate the costs of such rules.

In a related vein, many companies have begun to discover that environmental protection actually can be good for business in some respects. Increased energy efficiency, profitable products made from waste, and decreased use of raw materials are just a few of the costsaving or even profit-making results of turning more corporate atten-

49 E.g., Michael Kinsley, Bush Is Right on Arsenic. Dam!', WASH. POST, Apr. 13, 2001, at A23; Sebastian Mallaby, Saving Statistical Lives, WASH. POST, Mar. 5, 2001, at A19; George F. Will, The Costs of Moral Exhibitionism, WASH. POST, Apr. 15, 2001, at B7.

${ }^{50}$ Eban Goodstein \& Hart Hodges, Polluted Data: Overestimating Environmental Costs, Am. Prospect, Nov.-Dec. 1997, at 64, 64; see also HART Hodges, ECON. POL'Y InST,, FAlling PRICES: COST OF COMPlying WITH ENVIRONMENTAL REgulations ALMOST ALWAYS LESS THAN ADVERTISED (1997) (reporting on the same study).

${ }^{51}$ Winston Harrington et al., On the Accuracy of Regulatory Cost Estimates, 19 J. POL'Y ANALYSIS \& MGMT. 297, 306, 307 tbl.2 (2000).

${ }^{52}$ Pub. L. No. 101-549, tit. IV, 104 Stat. 2585 (1990).

${ }^{53}$ Goodstein \& Hodges, supra note 50, at 68. Nicholas Ashford's important work sounds a similar theme. E.g., NiCHOLAS A. ASHFORD \& CHARLES C. CALDART, TECHNOLOGY, LAW, AND THE WORKING ENVIRONMENT 506-07 (1991).

${ }^{54} I d$. 
tion to environmentally protective business practices. ${ }^{55}$ Cost-benefit analyses typically do not take such money-saving possibilities into account in evaluating the costs of regulation.

\section{THE MANY AlteRnatives to COST-BENEFIT ANALYSIS}

A common response to the criticisms of cost-benefit analysis is a simple question: what is the alternative? The implication is that despite its flaws, cost-benefit analysis is really the only tool we have for figuring out how much environmental protection to provide.

This is just not true. Indeed, for thirty years, the federal government has been protecting human health and the environment without relying on cost-benefit analysis. The menu of regulatory options that has emerged from this experience is large and varied. Choosing among these possibilities depends on a variety of case-specific circumstances, such as the nature of the pollution involved, the degree of scientific knowledge about it, and the conditions under which people are exposed to it. As the following brief sketch of alternatives reveals, cost-benefit analysis-a "one-size-fits-all" approach to regulationcannot be squared with the multiplicity of circumstances surrounding different environmental problems.

For the most part, environmental programs rely on a form of "technology-based" regulation, the essence of which is to require the best available methods for controlling pollution. This avoids the massive research effort needed to quantify and monetize the precise harms caused by specific amounts of pollution, which is required by cost-benefit analysis. In contrast, the technology-based approach allows regulators to proceed directly to controlling emissions. Simply put, the idea is that we should do the best we can to mitigate pollution we believe to be harmful.

Over the years, the EPA has learned that flexibility is a good idea when it comes to technology-based regulation and thus has tended to avoid specifying particular technologies or processes for use by regulated firms; instead, the agency increasingly has relied on "performance-based" regulation, which tells firms to clean up to a certain, specified extent, but does not tell them precisely how to do it. Technology-based regulation generally takes costs into account in determining the required level of pollution control but does not demand the kind of precisely quantified and monetized balancing process that

\footnotetext{
${ }^{55}$ For a recent report on this phenomenon, see Claudia H. Deutsch, Together at Last: Cutting Pollution and Making Money, N.Y. TimES, Sept. 9, 2001, at BU1.
} 
is needed for cost-benefit analysis.

Another regulatory strategy that has gained a large following in recent years is the use of "pollution trading," as in the sulfur dioxide emissions trading program created for power plants under the 1990 Clean Air Act Amendments. ${ }^{50}$ That program grants firms a limited number of permits for pollution, but allows them to buy permits from other firms. Thus, firms with high pollution control costs can save money by buying permits, while those with low control costs can save money by controlling emissions and selling their permits. The fixed supply of permits, created by law, sets the cap on total emissions; the trading process allows industry to decide where and how it is most economical to reduce emissions to fit under the cap. Trading programs have become an important part of the federal program for controlling pollution. These programs, too, have not used cost-benefit analysis in their implementation. Congress, the EPA, or other officials set the emissions cap, and the market does the rest.

It is theoretically possible that cost-benefit analysis could be used to choose the overall limit on pollution that guides both performancebased and market-based regulatory programs. However, this has not been standard practice in the past; the limit on sulfur emissions in the 1990 Clean Air Act Amendments, for example, was set by a process of political compromise. ${ }^{57}$ Given the problems with cost-benefit analysis, political compromise cannot be viewed as an inferior way to set a cap on emissions. Many regulatory programs have been a terrific success without using cost-benefit analysis to set pollution limits.

One last example (a desire for reasonable brevity prevents us from listing more) is informational regulation, which requires disclosures to the public and/or to consumers about risks they face from exposures to chemicals. These "right-to-know" regimes allow citizens and consumers not only to know about the risks they face, but also empower them to do something about those risks. The Toxic Release Inventory created by the Emergency Planning and Community Right-toKnow Act, ${ }^{58}$ the product warning labels required by California's "Proposition 65," and the consumer notices now required regarding

${ }^{56} 42$ U.S.C. $\$ \S 7651-76510$ (1994).

${ }^{57}$ Lisa Heinzerling, Selling Pollution, Forcing Democracy, 14 STAN. ENVTL. L.J. 300, 332 (1995).

${ }_{58}^{58} 42$ U.S.C. $\$ \$ 11001-11050$ (1994).

${ }^{59}$ The Safe Drinking Water and Toxic Enforcement Act of 1986, CAL. HEALTH \& SAFETY CODE $\$ \S 25249.5-25249.13$ (West 1999). 
drinking water that contains hazardous chemicals ${ }^{60}$ are all variants of this type of information-based regulation. Not one of these popular and effective programs relies on cost-benefit analysis.

The arguments for flexible technology-based regulation and for incentive-based programs like pollution trading and disclosure requirements are sometimes confused with the arguments for costbenefit analysis. But both technology-based and incentive-based regulation take their goals from elected representatives rather than from economic analysts, even though the means adopted by these regulatory strategies are strongly influenced by attention to costs. The current style of cost-benefit analysis, however, purports to set the ends, not just the means, of environmental policy, and that is where its aspirations amount to arrogance.

Economic analysis has had its successes and made its contributions; it has taught us a great deal over the years about how we can most efficiently and cheaply reach a given environmental goal. It has taught us relatively little, however, about what our environmental goals should be. Indeed, while economists have spent three decades wrangling about how much a human life, or a bald eagle, or a beautiful stretch of river is worth in dollars, ecologists, engineers, and other specialists have gone about the business of saving lives and eagles and rivers without waiting for formal, quantitative analysis proving that saving these things is worthwhile.

\section{CONCLUSION}

Two features of cost-benefit analysis distinguish it from other approaches to evaluating the advantages and disadvantages of environmentally protective regulations: the translation of lives, health, and the natural environment into monetary terms, and the discounting of harms to human health and the environment that are expected to occur in the future. These features of cost-benefit analysis make it a terrible way to make decisions about environmental protection, for both intrinsic and practical reasons.

Nor is it useful to keep cost-benefit analysis around as a kind of regulatory tag-along, providing information that regulators may find "interesting" even if not decisive. Cost-benefit analysis is exceedingly time- and resource-intensive, and its flaws are so deep and so large that this time and these resources are wasted on it. Once a cost-

${ }^{60} 42$ U.S.C. $\S 300 \mathrm{~g}-3$ (c) (4) (Supp II. 1996) (amending the Safe Drinking Water Act to require annual "consumer confidence reports"). 
benefit analysis is performed, its bottom line number offers an irresistible sound bite that inevitably drowns out more reasoned deliberation. Moreover, given the intrinsic conflict between cost-benefit analysis and the principles of fairness that animate, or should animate, our national policy toward protecting people from being hurt by other people, the results of cost-benefit analysis cannot simply be "given some weight" along with other factors, without undermining the fundamental equality of all citizens-rich and poor, young and old, healthy and sick.

Cost-benefit analysis cannot overcome its fatal flaw: it is completely reliant on the impossible attempt to price the priceless values of life, health, nature, and the future. Better public policy decisions can be made without cost-benefit analysis, by combining the successes of traditional regulation with the best of the innovative and flexible approaches that have gained ground in recent years. 